\title{
What Were the Cost Drivers for Publicly Accessible Charging Installations?
}

Idaho National Laboratory

June 2015

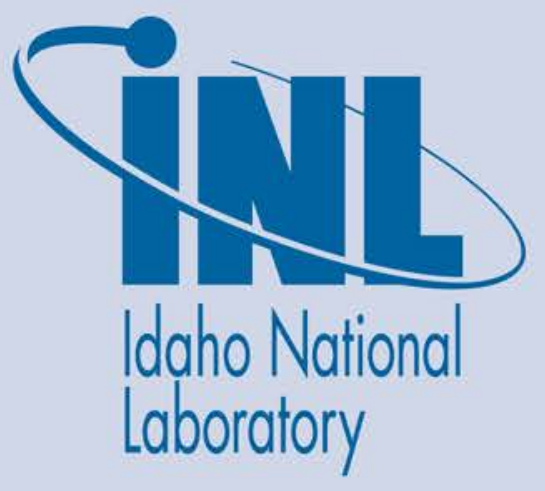

The INL is a U.S. Department of Energy National Laboratory operated by Battelle Energy Alliance 


\title{
What Were the Cost Drivers for Publicly Accessible Charging Installations?
}

Idaho National Laboratory

June 2015

\section{Idaho National Laboratory \\ Idaho Falls, Idaho 83415}

http://www.inl.gov

\author{
Prepared for the \\ U.S. Department of Energy \\ Assistant Secretary for __, OR Office of \\ Under DOE Idaho Operations Office \\ Contract DE-AC07-05ID14517
}




\section{What Were the Cost Drivers for Publicly Accessible Charging Installations?}

June 2015

\section{Key Conclusions}

- Average installation cost per unit for publicly accessible alternating current (AC) Level 2) electric vehicle supply equipment (EVSE) installed in The EV Project's markets was $\$ 3,108$.

- Installation cost of wall-mounted EVSE was 34\% less expensive than pedestal EVSE $(\$ 2,035$ versus $\$ 3,108)$.

- Variations in installation site conditions included the following:

- Distance between EVSE and power distribution panel

- Number units installed at the site

- The nature of the surface needing restoration as a result of installation.

The distance and surface condition variations had more impact on installation cost than the number of units installed per site.

\section{Introduction}

Publicly accessible EVSE stations in The EV Project are defined as those installed for businesses, institutions, and municipalities to provide charging for any plug-in electric vehicle (PEV). Typically, no formal relationship exists between the charging site host and the PEV driver utilizing the EVSE. Whereas, fleet, workplace, and residential charging stations are intended to serve a restricted population of PEVs with drivers formally related to the charging site host in some manner.

Costs for installation of publicly accessible EVSE units were an important consideration of The EV Project, because these costs had an impact on host participation and, subsequently, on the public's perception of PEV adoption.

In an effort to achieve the objective of establishing and studying a rich infrastructure of publicly accessible charging stations, The EV Project intended to make AC Level 2 EVSE free to the host; including installation. This would have reduced the economic influence on the host's decision to install a station at locations that the EV Micro-Climate ${ }^{\circledR}$ planning process identified as desirable. ${ }^{1}$
Although The EV Project provided a significant allowance toward the cost of installation, in many cases, actual installation costs exceeded that allowance. Other concerns from prospective charging site hosts included the observation that there were not enough PEVs to create demand for stations, and hosts were being requested to effectively eliminate a customer parking space to be designated for PEV charging.

This paper will examine the cost drivers associated with installation of publicly accessible EVSE charging stations.

\section{Data Analyzed}

Installation records prepared by The EV Project Field Services team and those provided by the electrical contractors that were employed to perform the installations provided the data used for this evaluation. The Field Services team had direct contact with the charging site hosts and electrical contractors regarding installation activities, from site selection, to permitting, and to hardware commissioning. This gave EV Project personnel direct experience with the entire charging station installation process.

Electrical contractors employed for installations were part of the Certified Contractor Network. The Certified Contractor Network was established and managed by The EV Project's Field Services team. It consisted of contractors selected in each of the market areas of The EV Project who were evaluated and trained for installation of Blink EVSE that were supplied by The EV Project. Contractors provided estimates, photographs, and invoice documents as part of their project documentation. These also contributed to the database used in this report.

\section{Discussion of Results}

\section{Non-Residential Electric Vehicle Supply Equipment}

To support PEV drivers and encourage PEV adoption, The EV Project provided AC Level 2 EVSE at each project participant's residence and at various non-residential locations, including publicly accessible areas. These publicly accessible locations were primarily public venues (e.g., shopping centers, parking facilities, restaurants, hotels, and transportation centers). This infrastructure was intended to provide charging for PEV drivers to enhance their driving experience, either through range extension or to provide relief from "range-anxiety." For PEVs that have no other source of motive power, range anxiety is concern that the battery will be depleted before the driver reaches the next charge opportunity. Therefore, the objective in selecting locations for publicly accessible charging infrastructure in The EV Project was to provide charging 
where PEV drivers were likely to park or where charging site hosts would like them to park, with some charging site hosts electing to install EVSE near their business with the objective of attracting PEV drivers.

In the first five markets of The EV Project, a local group of stakeholders participated in a detailed planning process called the EV Micro-Climate process ${ }^{2}$ that was developed by The EV Project. Local project personnel solicited charging site hosts in the desired geographic locations to support deployment of the charging infrastructure.

The EV Project provided free EVSE to the hosts and provided credit from $\$ 1,000$ to $\$ 3,500$ toward installation, depending on market costs.

A typical publicly accessible EVSE site included multiple charging stations. This was encouraged for the benefit of both PEV drivers (to assure availability of EVSE) and hosts (to attract more PEV drivers as customers for their business). The overall average number of EVSE per site in The EV Project was 2.58 units.

As shown in Table 1, installation cost data are available for 2,479 non-residential locations, with 2,201 of them being publicly accessible locations.

Table 1. Number of AC Level 2 non-residential EVSE units (classified by use type) with cost data available.

\section{Number of Non-Residential EVSE with Installation Cost Data}

\begin{tabular}{lccc} 
& $\begin{array}{c}\text { All Non- } \\
\text { Residential }\end{array}$ & $\begin{array}{c}\text { Publicly } \\
\text { Accessible }\end{array}$ & Workplace \\
\hline All & 2,479 & 2,201 & 278 \\
Pedestal Units & 2,056 & 1,853 & 203 \\
Wall Mount Units & 423 & 348 & 75 \\
\hline
\end{tabular}

The total number of non-residential AC Level 2 EVSE that was reported as installed during The EV Project was 4,327. Appendix A, Table A1 contains the number by EV Project market. As can be seen from Table 1, cost data were not available for all EVSE installations.

\section{Installation Cost}

The installation costs analyzed in this document are intended to be total installation costs and include all costs invoiced by the installation contractor. This includes costs invoiced to The EV Project AND those invoiced to the charging site host. These costs would typically include the contractor's installation and administration labor, permit fees, subcontractor costs (e.g., masonry, trenching, boring, striping, and landscaping), and materials (other than the EVSE units, which were provided by The EV Project).

The average cost to install publicly accessible EVSE was $\$ 3,108$ per unit installed. Table 2 summarizes the average installation cost for the AC Level 2 non-residential EVSE and further breaks down these average installation costs by type of use.

Table 2. Average Installation costs for EV Project nonresidential AC Level 2 EVSE.

\begin{tabular}{lccc}
\hline & $\begin{array}{c}\text { Average Installation Cost } \\
\text { All Non- } \\
\text { Residential }\end{array}$ & $\begin{array}{c}\text { Publicly } \\
\text { Accessible }\end{array}$ & Workplace \\
\hline All & $\$ 2,979$ & $\$ 3,108$ & $\$ 2,223$ \\
Pedestal Units & $\$ 3,209$ & $\$ 3,308$ & $\$ 2,305$ \\
Wall Mount Units & $\$ 2,035$ & $\$ 2,042$ & $\$ 2,000$ \\
\hline
\end{tabular}

Variation in this cost by EV Project market is shown in Figure 1 and discussed further in another paper titled, "How did publicly accessible installation costs vary by geographic location?"3 Installation costs per unit for publicly accessible EVSE varied from $\$ 600$ to $\$ 12,600$ per unit; however the majority (i.e., $76.2 \%$ ) of the EVSE was installed at a cost between $\$ 1,000$ and $\$ 4,000$ per unit. Distribution of per unit installation costs for publicly accessible EVSE is shown graphically in Figures 1, 2, and 3.

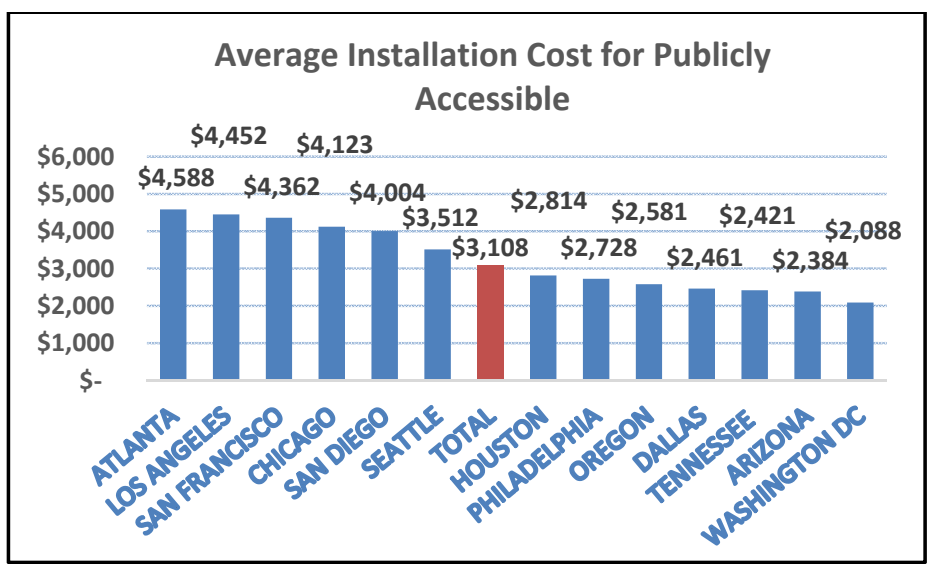

Figure 1. Average installation cost for publicly accessible EVSE by EV Project market.

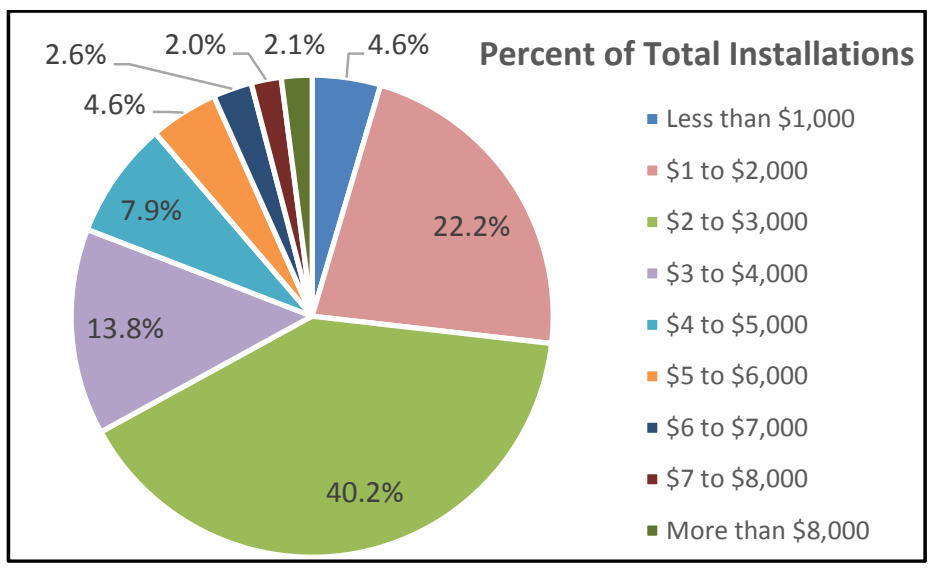

Figure 2. Percentage of the number of installations at each installation cost level. 


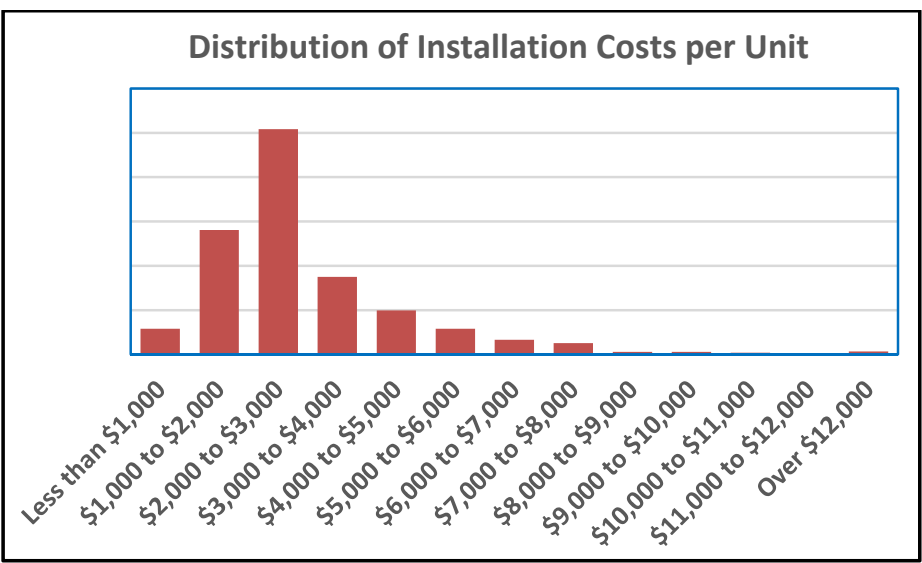

Figure 3. Distribution of average per unit installation costs.

Some potential charging site hosts declined to participate because their share of installation costs would have been unacceptably high.

It is worthwhile to note that The EV Project provided an installation cost allowance of $\$ 2,250$ per unit for most of the installed units. However, the installation cost allowance was reduced as additional markets were introduced in The EV Project. At the original allowance level, $42 \%$ of the units would have been installed at no financial cost to the host.

\section{Installation Cost Drivers}

Installation cost drivers for publicly accessible EVSE were influenced by the need for EVSE to be more easily located by PEV drivers who may not be familiar with the location of EVSE or the general area. This meant that EVSE were more likely to be found in prominent locations. These prominent locations often placed them in places that resulted in higher installation costs.

Major cost drivers for publicly accessible EVSE considered in this document are as follows:

- Location of EVSE relative to site electrical services

- Nature of surface onto or under which the electrical conduit is installed

- Number of EVSE installed.

\section{Location of Electric Vehicle Supply Equipment on the Host Site}

In most cases, the lowest cost location on the host's property for installing EVSE was at the rear of the building nearer to the electrical service panel, with units mounted as close as practical to the building. However, the best location for installing EVSE intended to be publicly accessible is typically the most visible location to a PEV driver approaching the host's facility from public roads.

Therefore, most publicly accessible EVSE were installed in more prominent locations. This often meant at the front of buildings rather than at the rear where electrical service is more frequently found.

Often times it also meant installation at or near handicapped accessible parking spaces at the front of buildings if local authorities having jurisdiction specified Americans with Disabilities Act parking accessibility for EVSE charging spaces. In these cases, there were also considerations for lost parking places as standard width spaces were expanded to meet Americans with Disabilities Act requirements. ${ }^{4}$

Installation in these desirable locations for public accessibility usually meant longer conduit runs, which would mean not only more wire and conduit, but also longer trenches, more concrete or asphalt to repair and so forth.

\section{Nature of Installation Surface}

As identified in the previous section, the prominent location for publicly accessible EVSE was not only a longer distance from electrical services to the building, but it also tended to be on or through more expensive surfaces upon which to install the unit or its associated electrical conduit.

Appendix A contains photographic examples of the variety of installation conditions encountered by The EV Project.

Figures 4, A1, A2, and A3 show EVSE being installed in landscaped environments, requiring underground boring or special restoration efforts after completion of the conduit installed under these landscaped surfaces.

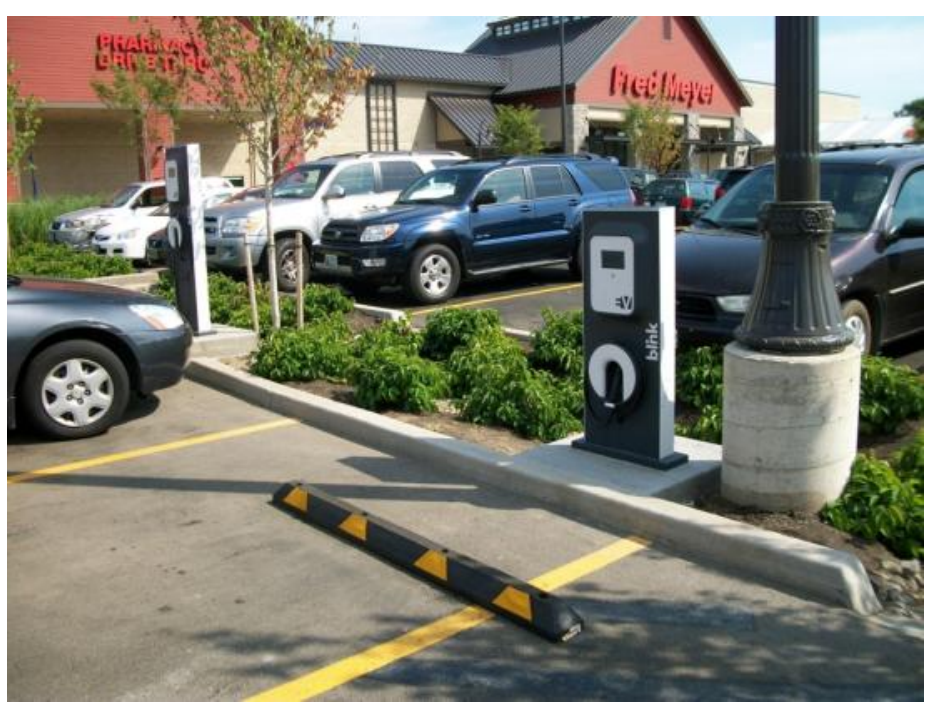

Figure 4. Publicly accessible AC Level 2 EVSE installed in a prominent location on the host's property.

Meanwhile, locations far away from buildings and the associated electrical distribution panels, as can be seen in Figures A4 and A5, included expensive restoration costs 
for concrete and asphalt surfaces and long runs of conduit and electrical conductors.

When surface-mounted conduit was a feasible solution, EVSE installation costs tended to be lower.

Surface-mounted conduit was more typical of a wall-mounted EVSE than a pedestal-mounted EVSE. As shown in Figure 5, regions of The EV Project with the most wall-mount EVSE installations (surface-mounted conduit intensive) had the lowest average installation cost. In Figure 5, The EV Project markets on the x-axis are in order (left-to-right) from most expensive average installation cost to the least expensive, while the $y$-axis is the percentage of wall-mounted units amongst all non-residential EVSE installations.

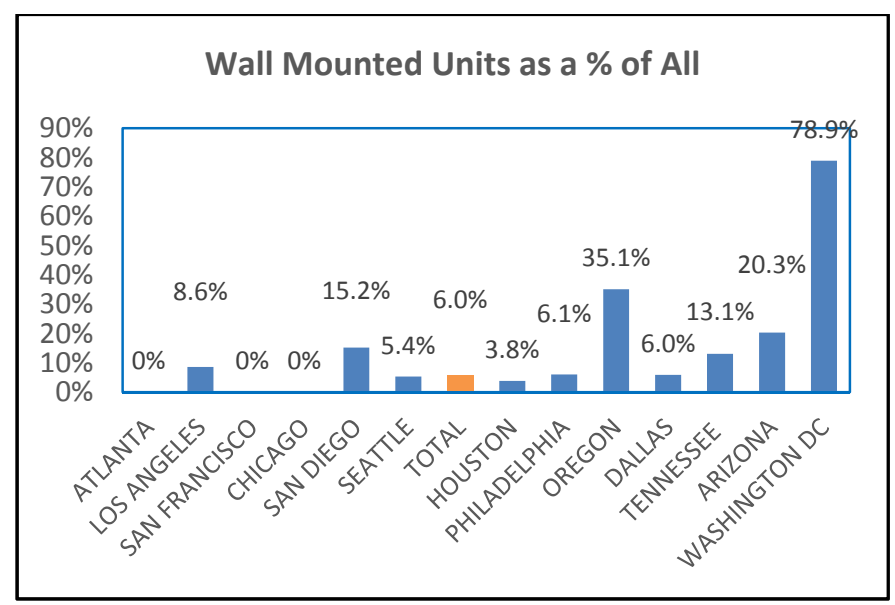

Figure 5. Wall-mounted units as a percentage of all non-residential units deployed.

Examples of the various installations with wall-mounted EVSE and surface-mounted conduit can be seen in the photographs in Appendix A as Figures A6, A7, A8, and A9. Some locations where pedestal units could be installed with surface-mounted conduit are seen in Figures A10 and A11.

\section{Number of Electric Vehicle Supply Equipment}

One of the common expectations regarding installation costs for AC Level 2 EVSE was that installing more units at a site was a "per-unit" cost reduction. Installation cost data from The EV Project somewhat supports this expectation. Figure 6 shows the cost per unit based on the number of units installed at a particular site or address. As the figure shows, there is a decrease in per-unit costs after two units, but those savings are not particularly significant.

In addition, the per-unit cost to install two EVSE units was the most expensive per unit installation cost.

Although detailed cost data are not available to explain this, one possible explanation could have to do with existing electrical service. One can assume that all commercial buildings would have sufficient capacity in their electrical distribution panel to add a single 40-ampere circuit required for the Blink ACL2 EVSE. Therefore, an upgrade to the electrical service would not be required. However, this may not be the case when two or more EVSE are installed. The cost to upgrade the host electrical service would add a significant increment to installation cost. The cost to upgrade the electrical service to power two circuits or five circuits would be approximately the same, resulting in the largest step up in cost for two EVSE.

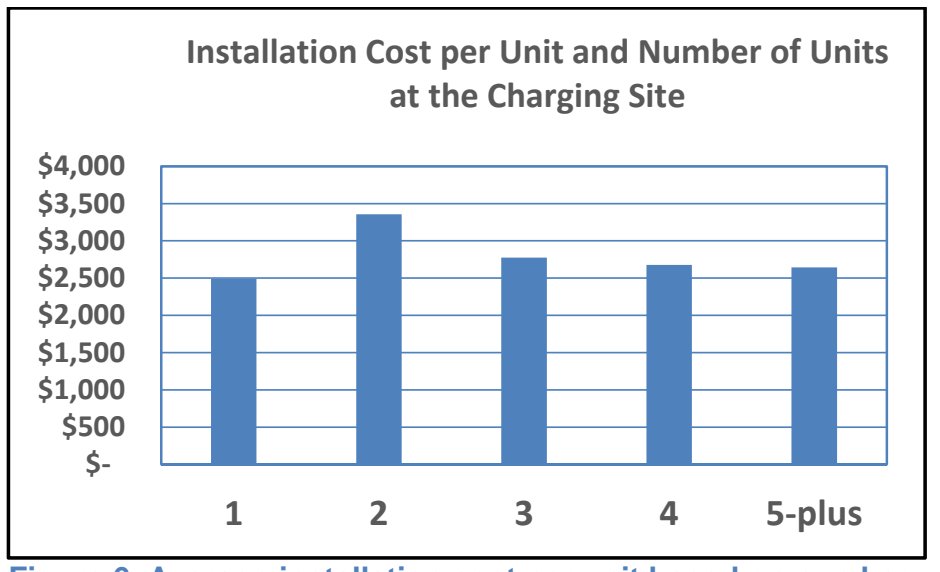

Figure 6. Average installation cost per unit based on number of units installed at the publicly accessible charging site

Similar to direct current fast charger installation costs, ${ }^{5}$ the need to modify the site's electrical service to accommodate the EVSE was a major installation cost driver. However, unlike the direct current fast charger, the number of EVSE installed and the associated electrical load could be adjusted, which could help the host avoid some costs. That is, the host could install the number of EVSE units that was within the existing site's electric service capacity.

The decision on the number of EVSE to install on a site could also be influenced by the desire to avoid demand charges and often be necessitated by an analysis of the host's overall power requirements. The impact from demand charges is discussed in another paper titled, Demand and Energy Characteristics of Non-Residential Alternating Current Level 2 Electric Vehicle Supply Equipment. 6

\section{Conclusions}

Installation costs for publicly accessible EVSE were driven higher by requirements associated with accessibility and visibility. Higher costs primarily were the result of greater distances from the EVSE to the electrical power source and disruption and repair of the ground surfaces on or under where the unit and electrical conduit were installed. Power requirements associated with the number of units installed also influenced overall installation costs for publicly accessible EVSE. 
The least expensive installations included surface-mounted conduit, a short conduit length, and used the existing site's electrical capacity. This is true of all non-residential EVSE installations, but is more difficult to achieve when public accessibility is considered.

\section{About The EV Project}

The EV Project was the largest PEV infrastructure demonstration project in the world, equally funded by the United States Department of Energy (DOE) through the American Recovery and Reinvestment Act and private sector partners. The EV Project deployed over 12,000 AC Level 2 charging stations for residential and commercial use and over 100 dual-port direct current fast chargers in 17 U.S. regions. Approximately 8,300 Nissan LEAFs ${ }^{\mathrm{TM}}$, Chevrolet Volts, and Smart ForTwo Electric Drive vehicles were enrolled in the project.

Project participants gave written consent for EV Project researchers to collect and analyze data from their vehicles and/or charging units. Data collected from the vehicles and charging infrastructure represented almost 125 million miles of driving and 4 million charging events. The data collection phase of The EV Project ran from January 1, 2011, through December 31, 2013. Idaho National Laboratory is responsible for analyzing the data and publishing summary reports, technical papers, and lessons learned on vehicle and charging unit use.

\section{Company Profile}

Idaho National Laboratory is one of DOE's

10 multi-program national laboratories. The laboratory performs work in each of DOE's strategic goal areas: energy, national security, science, and the environment. Idaho National Laboratory is the nation's leading center for nuclear energy research and development. Day-to-day management and operation of the laboratory is the responsibility of Battelle Energy Alliance.

For more information, visit avt.inl.gov/evproject.shtml and avt.inl.gov/chargepoint.shtml.

\section{References}

1. http://avt.inl.gov/evproject.shtm|\#LessonsLearned, "The EV Micro-Climate Planning Process."

2. Ibid.

3. http://avt.inl.gov/evproject.shtml\#LessonsLearned, "How Did Publicly Accessible Installation Costs Vary by Geographic Location?"

4. http://avt.inl.gov/evproject.shtml\#LessonsLearned, "Accessibility at Public Electric Vehicle Charging Locations."

5. http://avt.inl.gov/evproject.shtml\#LessonsLearned, "What Were the Cost Drivers for Direct Current Fast Charging Installations?"

6. http://avt.inl.gov/evproject.shtm|\#LessonsLearned, "Demand and Energy Characteristics of NonResidential Alternating Current Level 2 Electric Vehicle Supply Equipment." 


\section{EVProject}

\section{Appendix A}

Table A1. Installation cost data available for analysis and total number of EVSE reported as installed by The EV Project in August 2013.

\begin{tabular}{|l|c|c|c|}
\hline \multicolumn{1}{|c|}{ Market } & $\begin{array}{c}\text { Installed per EV Project } \\
\text { Status Report } \\
\text { August 2013 }\end{array}$ & $\begin{array}{c}\text { Installation Cost Data } \\
\text { Available }\end{array}$ & $\begin{array}{c}\text { Percentage of } \\
\text { Installation Data } \\
\text { Available for Analysis }\end{array}$ \\
\hline Atlanta & 202 & 141 & $69.8 \%$ \\
\hline Los Angeles & 440 & 208 & $47.3 \%$ \\
\hline San Francisco & 168 & 110 & $65.5 \%$ \\
\hline Chicago & 25 & 19 & $76.0 \%$ \\
\hline San Diego & 634 & 361 & $56.9 \%$ \\
\hline Seattle & 398 & 165 & $41.5 \%$ \\
\hline Houston & 134 & 52 & $38.8 \%$ \\
\hline Philadelphia & 75 & 33 & $44.0 \%$ \\
\hline Oregon & 527 & 437 & $82.9 \%$ \\
\hline Dallas & 433 & 167 & $38.6 \%$ \\
\hline Tennessee & 621 & 130 & $20.9 \%$ \\
\hline Arizona & 631 & 618 & $97.9 \%$ \\
\hline Washington DC & 39 & 38 & $97.4 \%$ \\
\hline Total & 4,327 & 2,479 & $57.3 \%$ \\
\hline
\end{tabular}




\section{Photographs of various installation conditions for Publicly Accessible Blink AC Level 2 EVSE}

(all photographs courtesy of The EV Project)

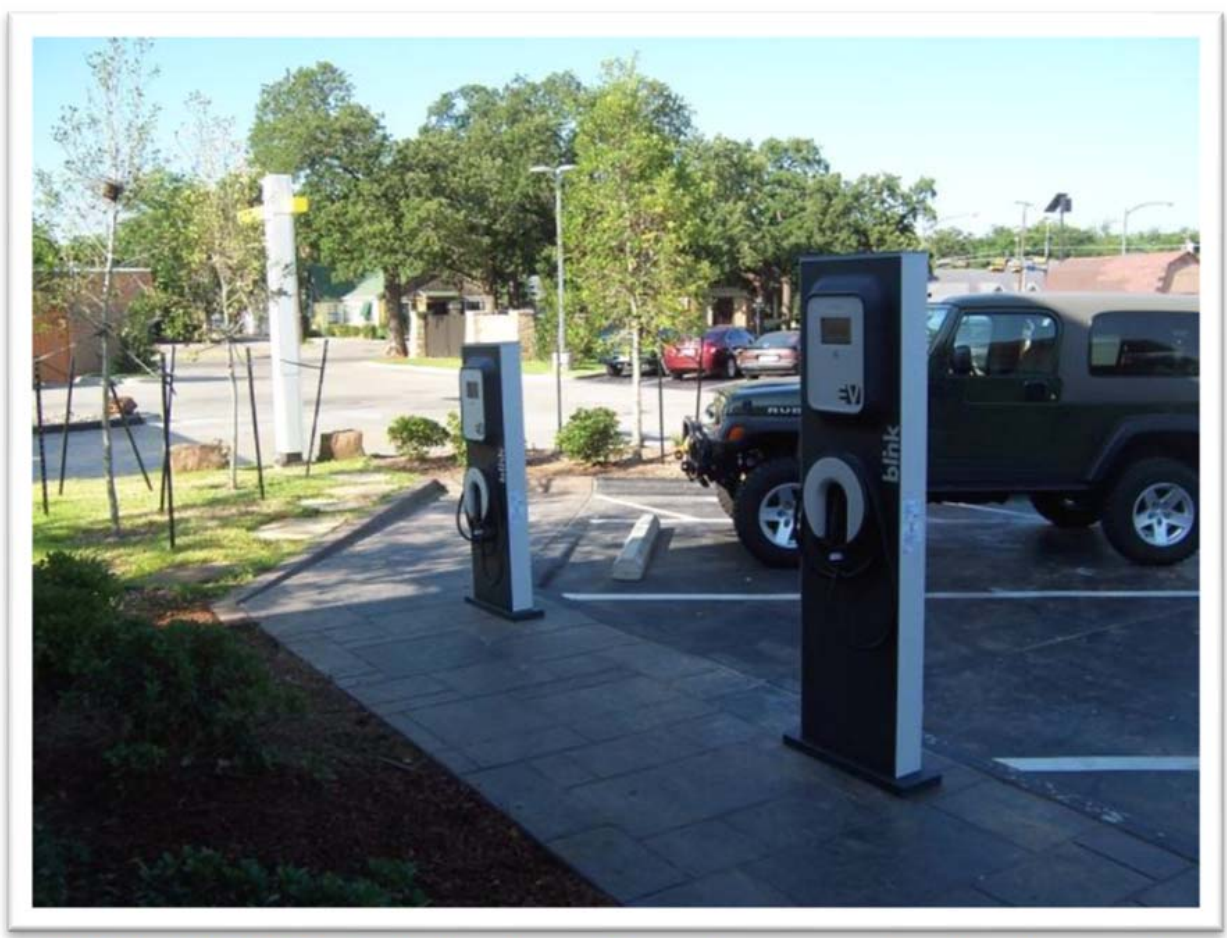

Figure A1. Pedestal EVSE installed on decorative paving; removal and replacement required for underground conduit.

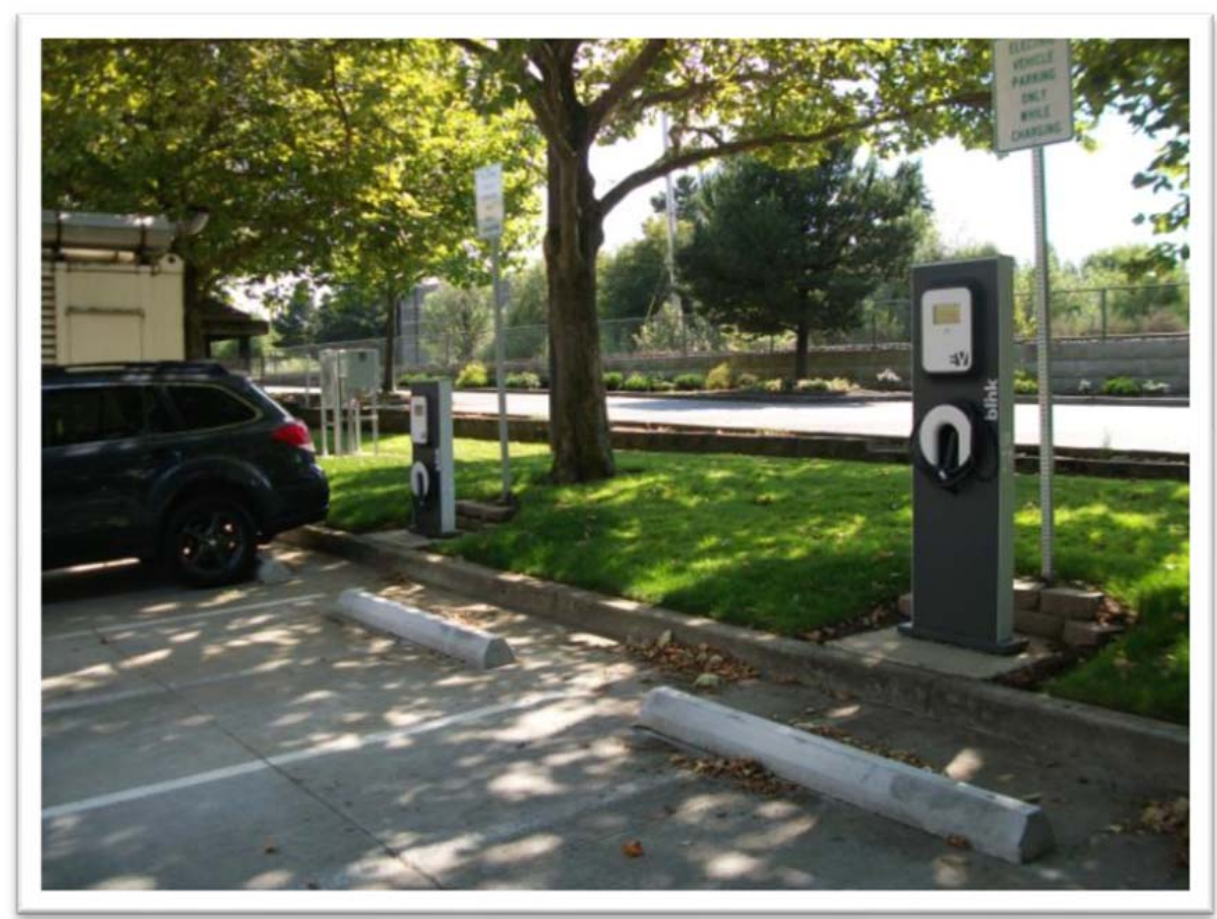

Figure A2. Pedestal EVSE installed on concrete pad, with underground boring for conduit. 


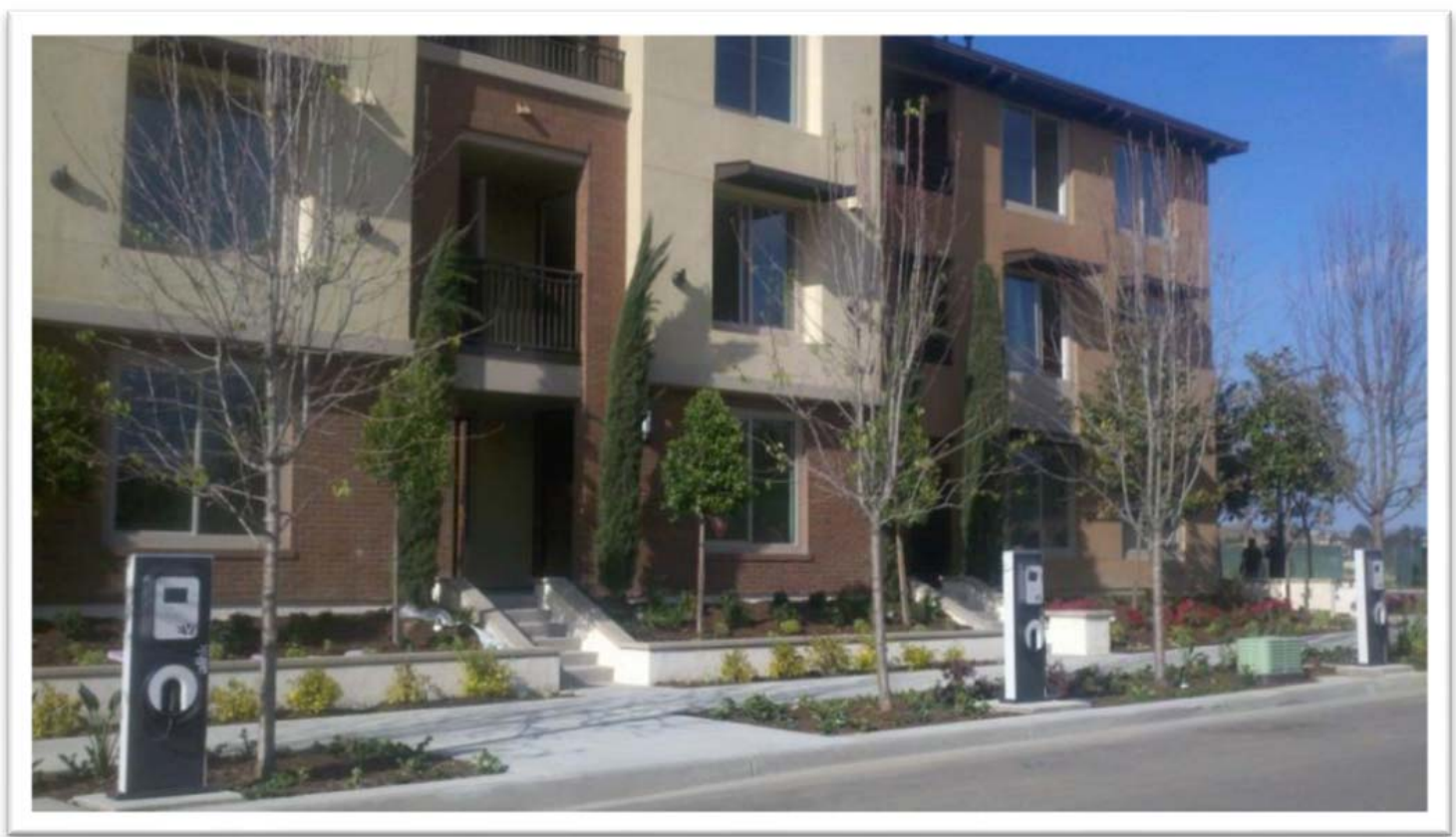

Figure A3. Pedestal EVSE installed street-side on concrete pad, within landscaped grounds.

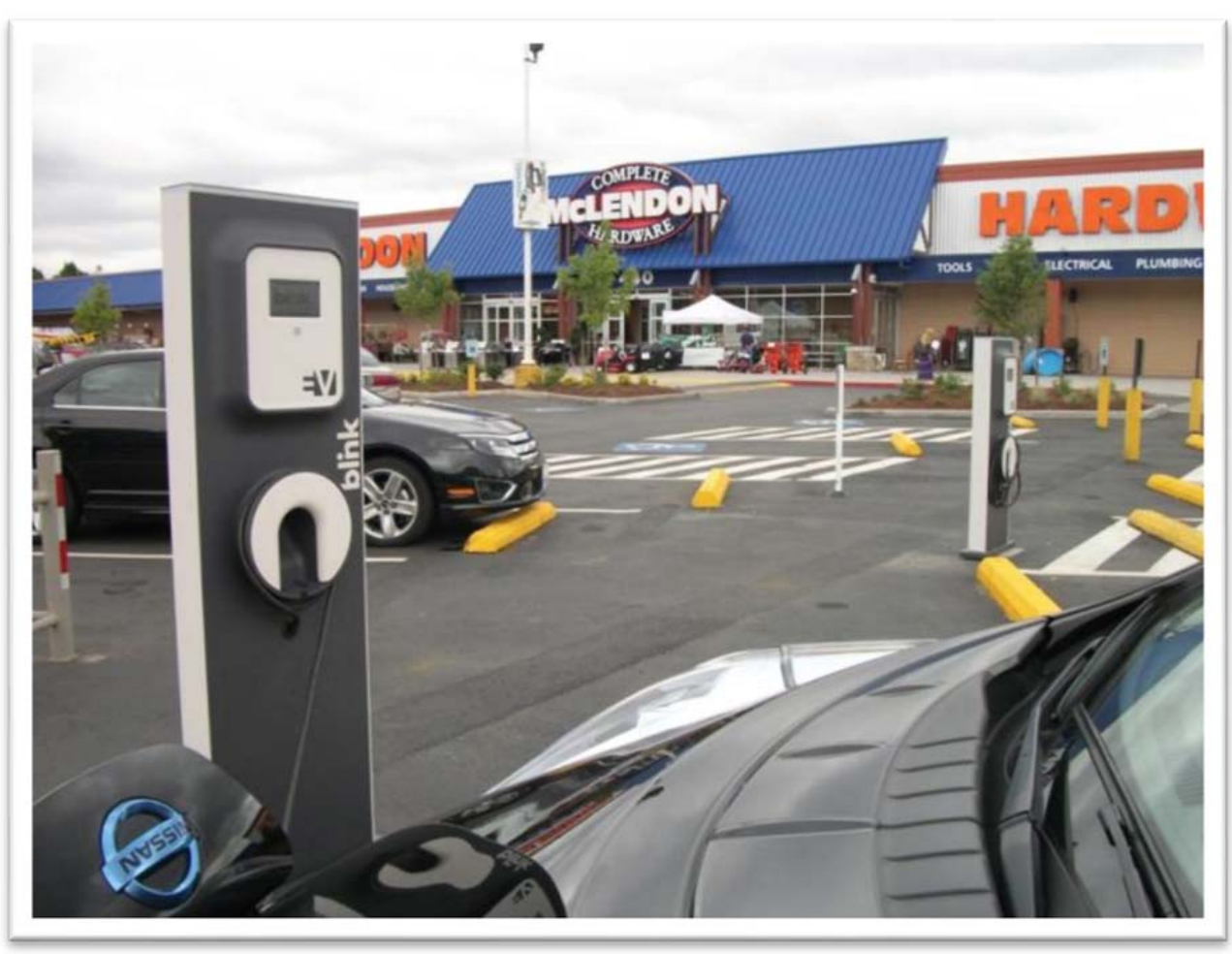

Figure A4. Pedestal EVSE installed on asphalt, with trenching and repaving for underground conduit. 


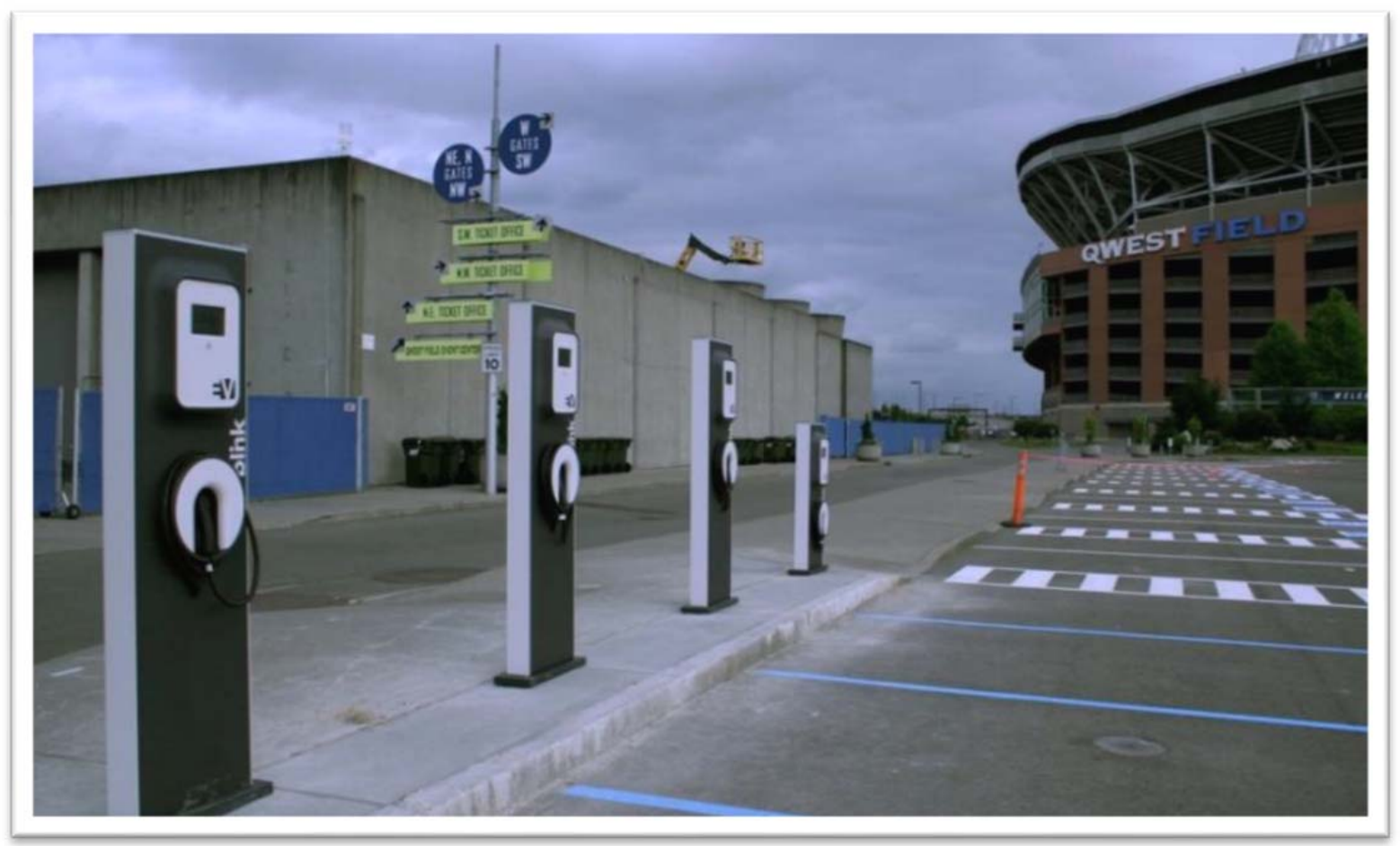

Figure A5. Pedestal EVSE installed on concrete sidewalk, requiring breaking out and re-pouring concrete for underground conduit.

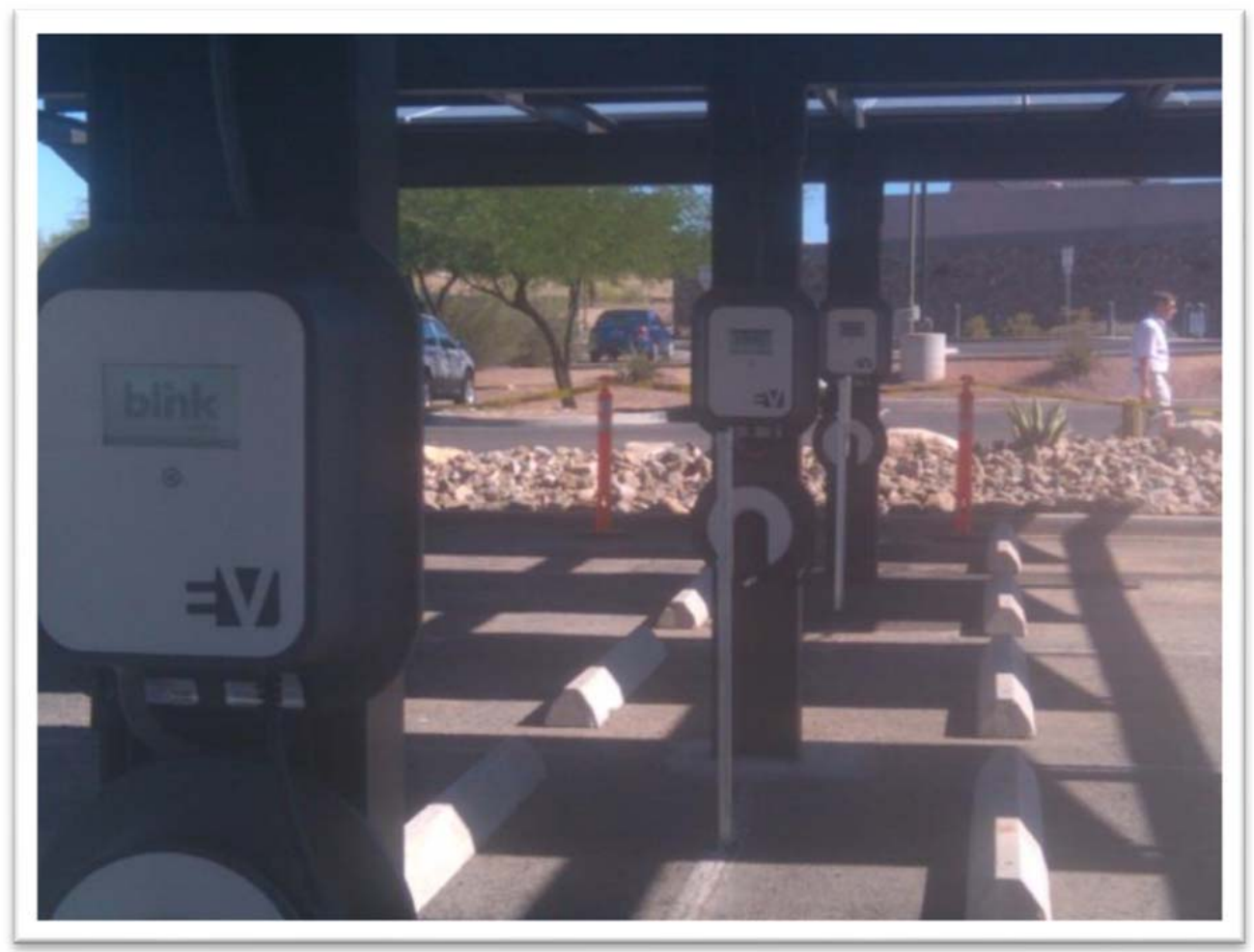

Figure A6. Wall-mount EVSE installed on building pillars with overhead surface mounting for conduit. 


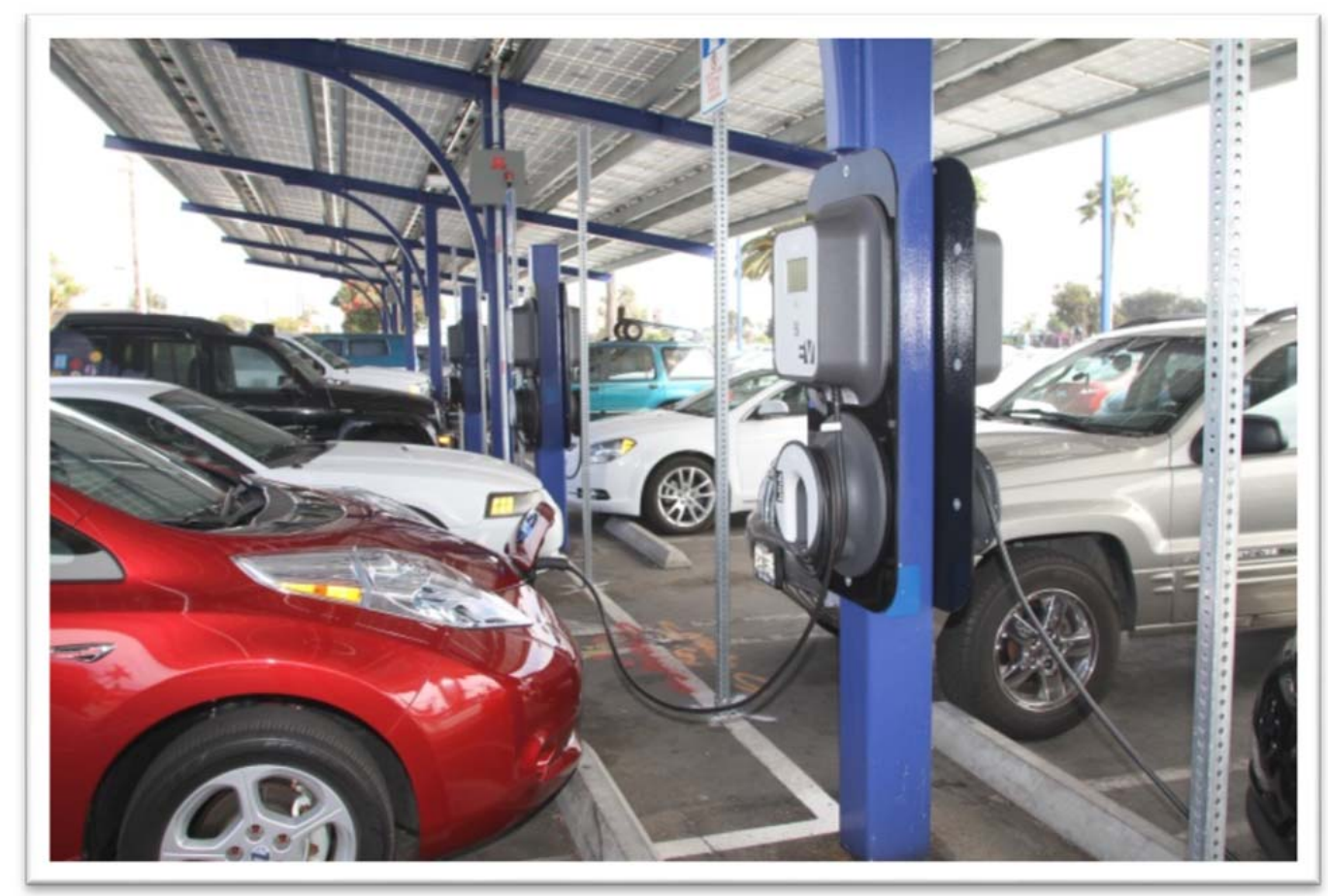

Figure A7. Wall-mount EVSE installed on building pillar with backing plate and overhead surface mounting for conduit.

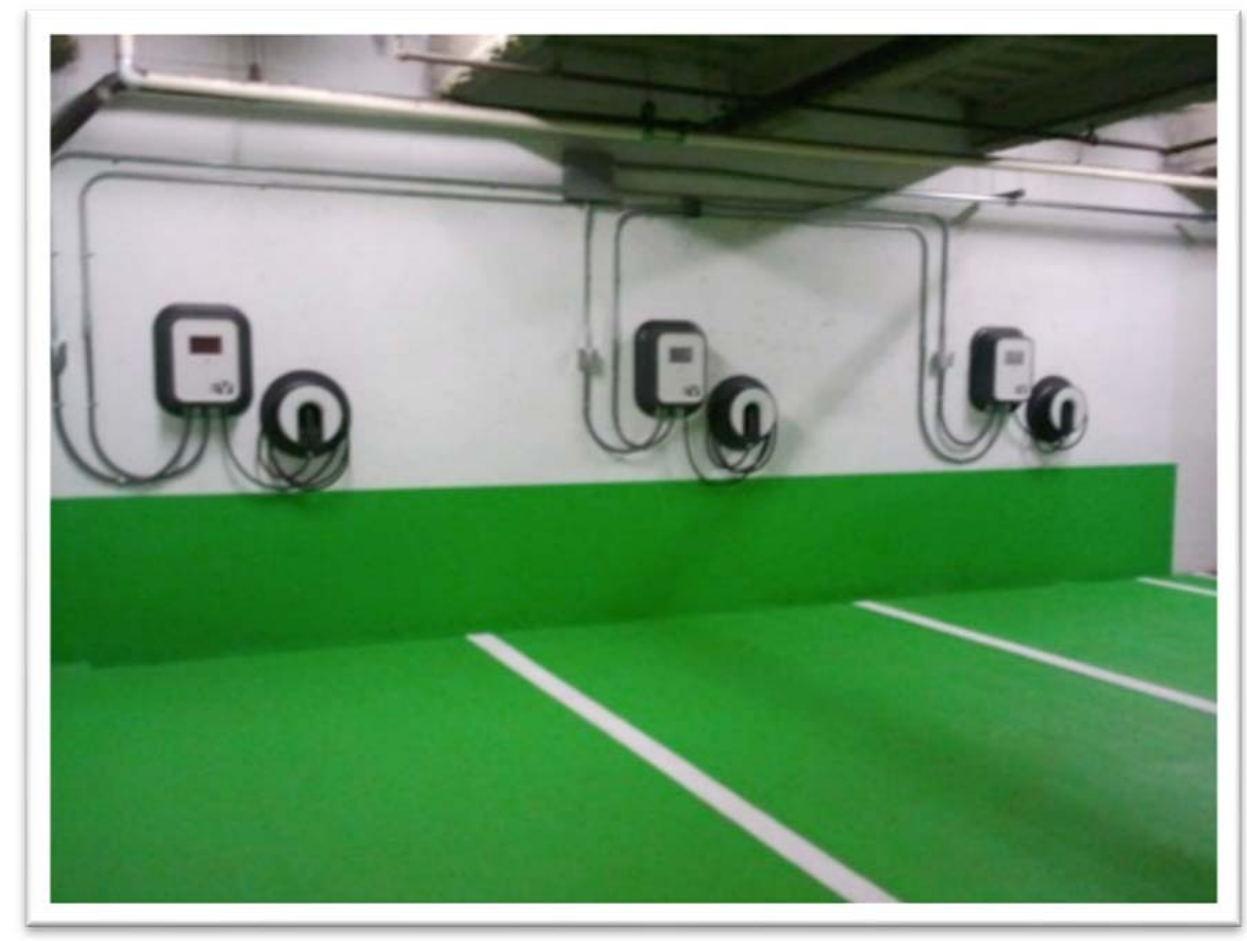

Figure A8. Wall-mounted EVSE installed in parking garage with overhead surface-mounted conduit. 


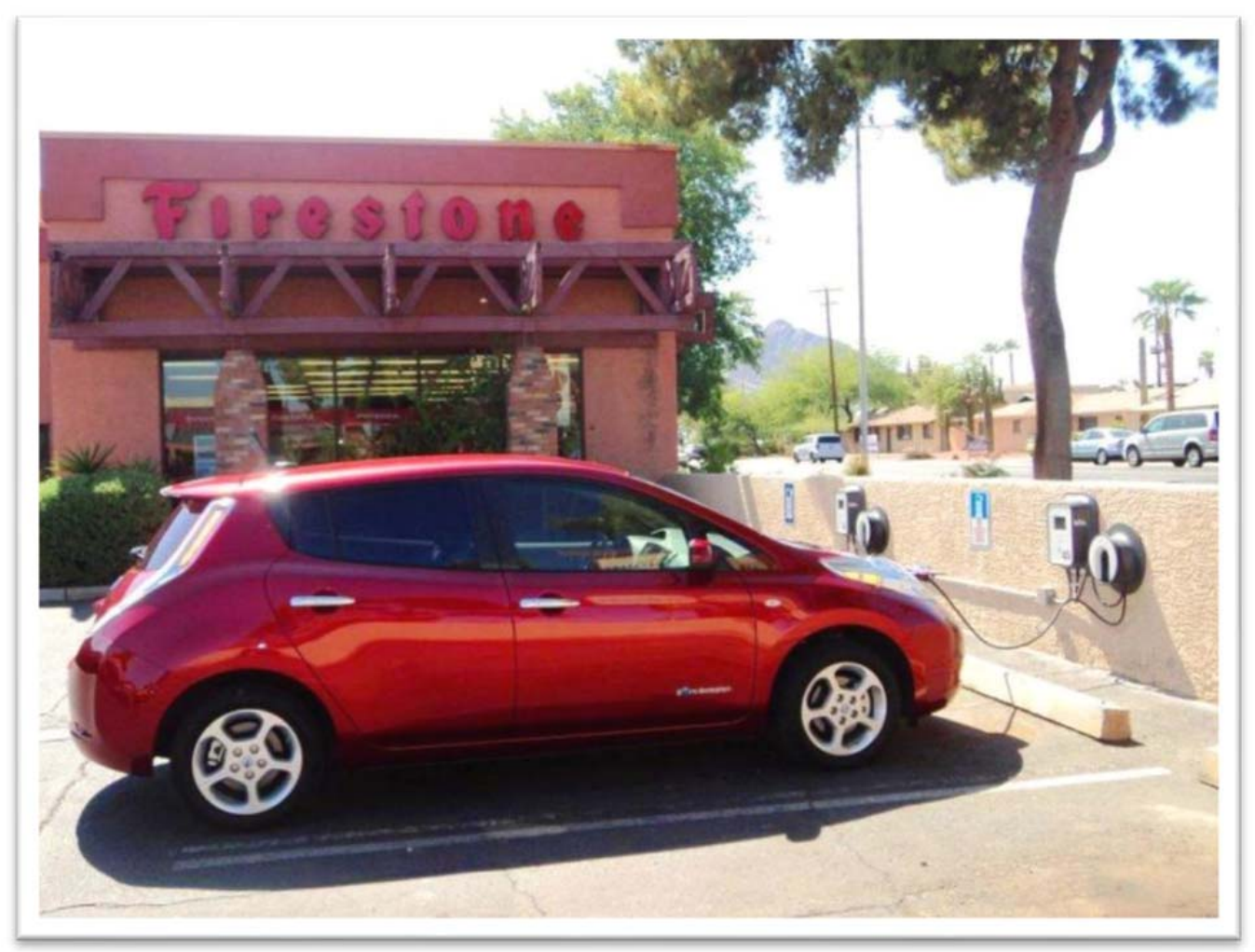

Figure A9. Wall-mounted EVSE installed on block divider wall with surface mounted conduit.

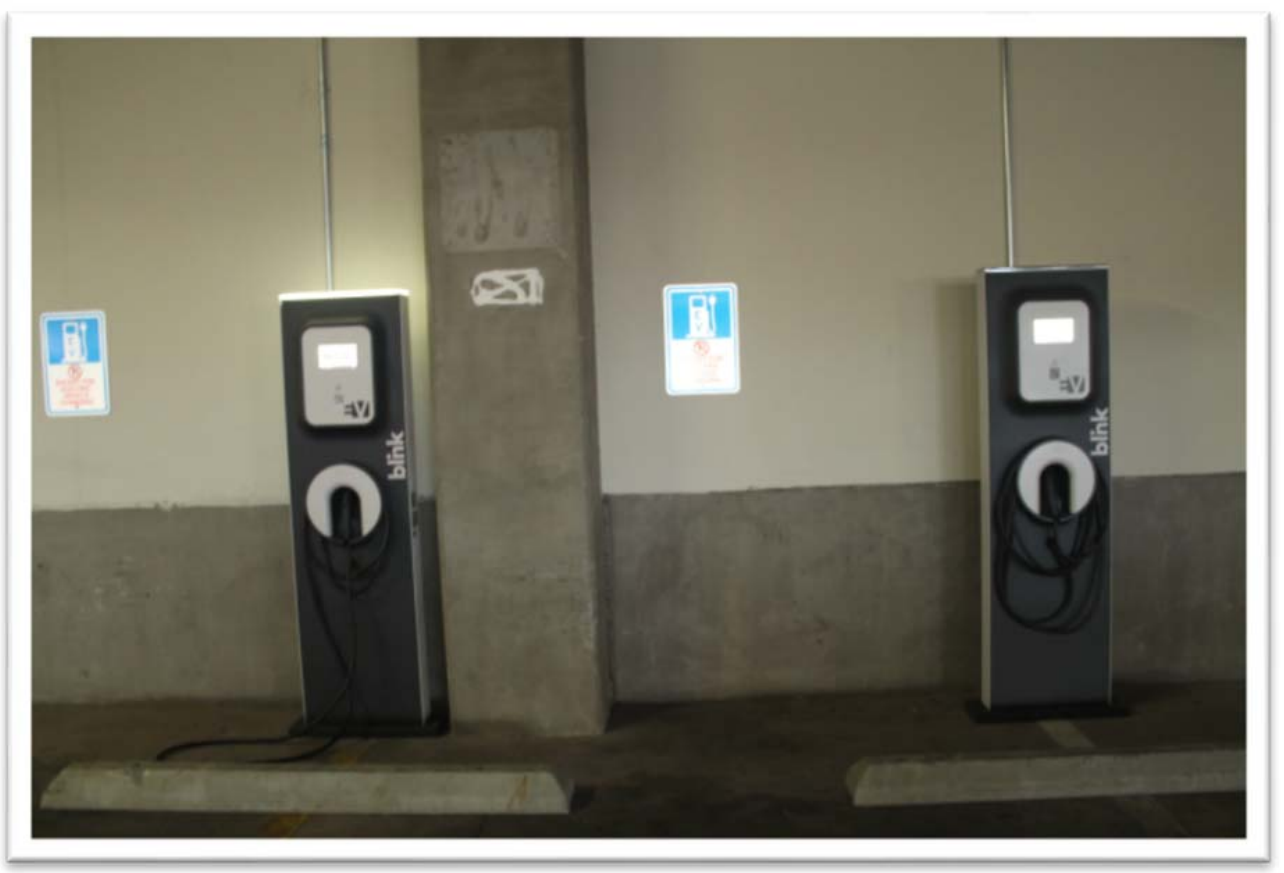

Figure A10. Pedestal EVSE installed in parking garage with overhead surface-mounted conduit. 


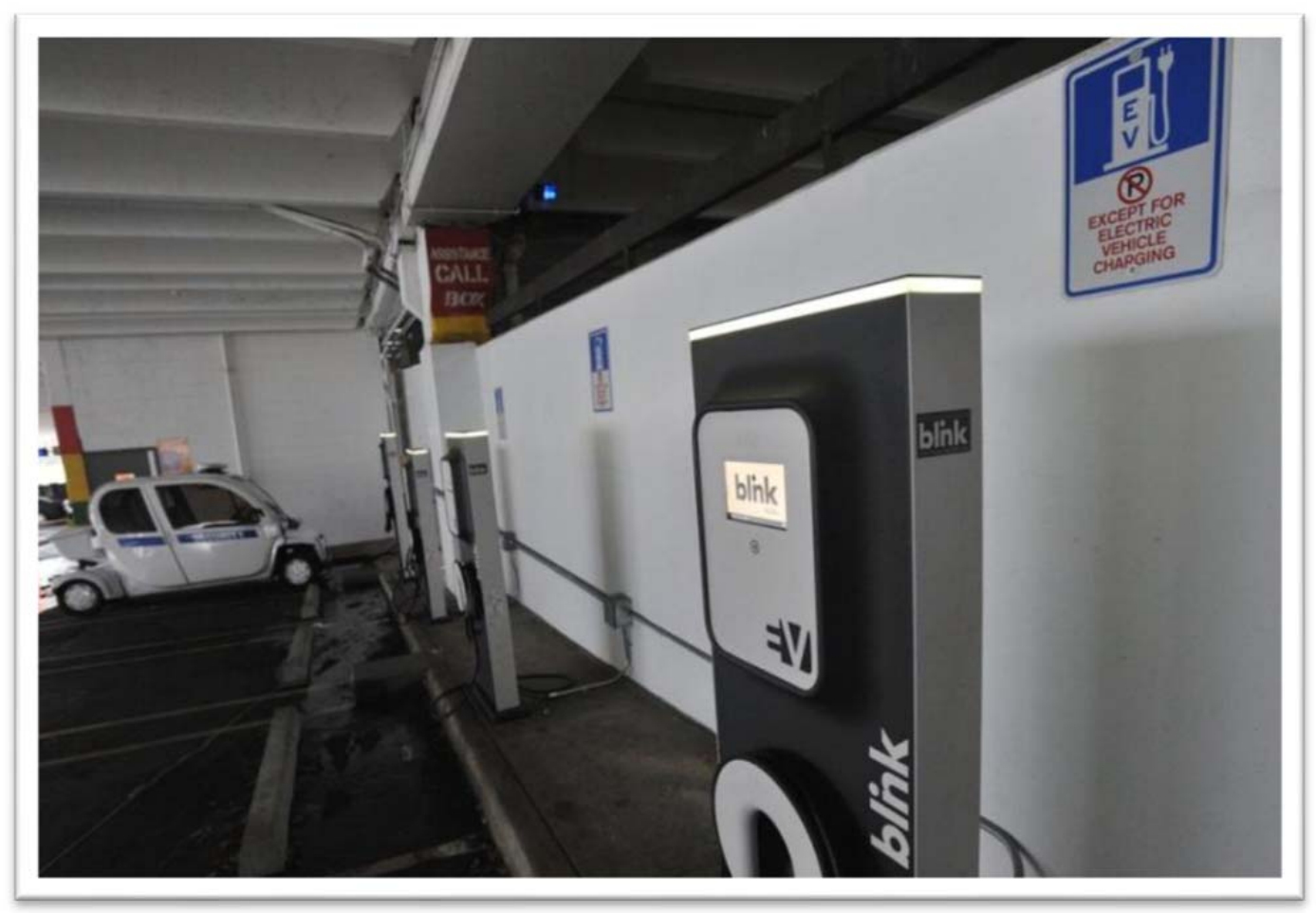

Figure A11. Pedestal EVSE installed in parking garage with wall-level, surface-mounted conduit.

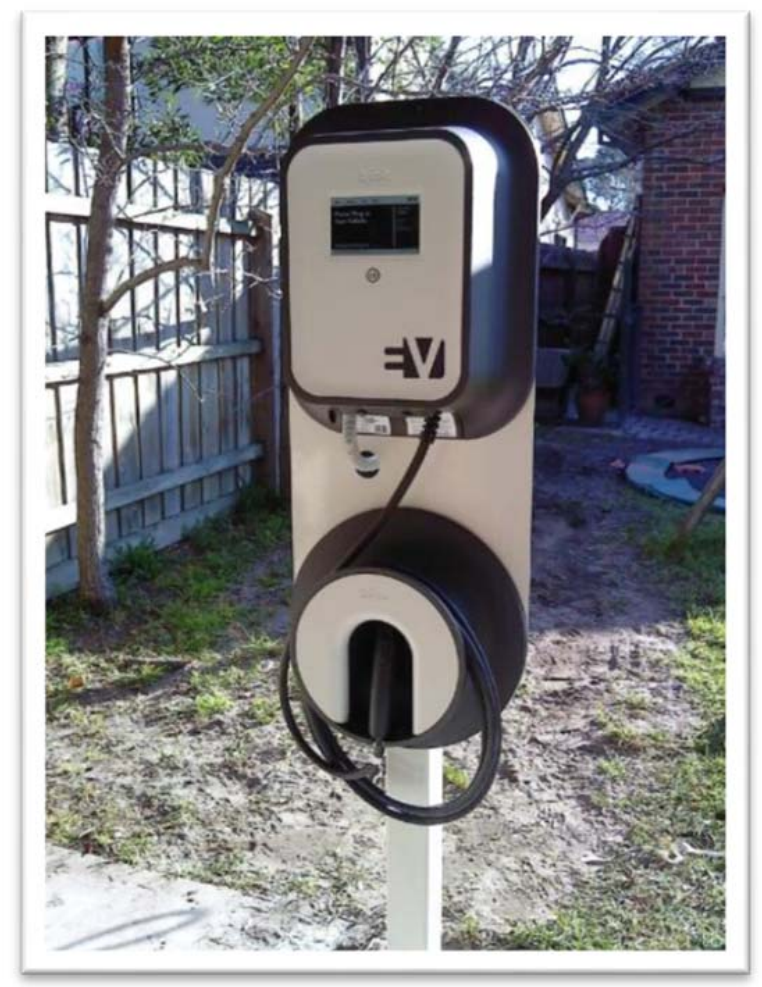

Figure A12. Wall-mount EVSE installed on a post with backing plate. Conduit installation trenched and recovered with soil like pedestal. 